\title{
XRD Studies of Thermally Stable Mesoporous Tungsten Oxide Synthesised by a Templated Sol-gel Process from Tungstic Acid Precursor
}

\author{
Wei Wang, Yongxin Pang, Simon Hodgson* \\ School of Science and Technology, University of Teesside, Middlesbrough, Tees \\ Valley TS1 3BA, UK
}

\begin{abstract}
Thermally stable mesoporous tungsten oxide film was prepared by a surfactant templated sol-gel method using tungstic acid as tungsten source. By careful selection of suitable non-ionic surfactant and heating processes, thermally stable mesostructured tungsten oxide films can be obtained, capable of withstanding heat treatment at temperatures of more than $400{ }^{\circ} \mathrm{C}$. The results show that tungstic acid is a suitable alternative precursor to the tungsten hexachloride normally reported in the literature for the preparation of mesostructured tungsten oxide. This work opens a new pathway for the preparation of mesoporous tungsten oxide films using tungstic acid precursor with many advantages including reduced cost, easy handling, and insensitivity to moisture.
\end{abstract}

Keywords: Mesoporous, Tungsten oxide, Tungstic acid, Sol-gel process

\section{Introduction}

In recent years, tungsten trioxide $\left(\mathrm{WO}_{3}\right)$ has attracted considerable interest, as a promising candidate utilised for catalysis [1] and photo-oxidation of water [2], gas sensing [3] and as the most extensively studied electrochromic material [4]. Such $\mathrm{WO}_{3}$ films are already integrated in commercial electrochromic devices such as smart windows and displays [5],

Tungsten trioxide films can be synthesised by different physical and chemical techniques such as laser ablation [6], anodic oxidation [7], sputtering [8], electrodeposition [9], and sol-gel processing [5, 10]. As a result, there is a reasonable understanding of how the preparation method and microstructure influence the most interesting electrochromic behaviour. The sol-gel method, in comparison to the above-mentioned preparation methods, has many advantages, i.e. it is inexpensive, simple and can be carried out under normal atmosphere. Additionally, enhanced sol-gel processes have been used to synthesise mesoporous materials with high surface area, exploiting self-assembly and templating effects of various surfactants

\footnotetext{
${ }^{*}$ Corresponding author: Prof. Simon Hodgson, School of Science and Technology, University of Teesside, UK. Tel: +44 (0)1642 384314, Fax: +44(0)1642 342401, Email: s.n.hodgson@tees.ac.uk
} 
$[11,12]$.

Importantly, it has been demonstrated that nanostructured tungsten oxide exhibits improved photochromic properties in comparison to dense films, with this enhancement usually believed to result from their greatly increased surface area which provides large quantities of active area to react [13]. With regard to the methods for developing mesostructures, it is now well established that surfactant templating sol-gel methods can be successfully employed to synthesise a number of metal oxides, including $\mathrm{WO}_{3}$ [14]. Cheng and co-workers further proved that mesoporous structured $\mathrm{WO}_{3}$, generated by a block copolymer templated sol-gel method, based on a $\mathrm{WCl}_{6}$ precursor, exhibited better kinetics for colouration and bleaching in comparison to the standard sol-gel derived tungsten oxide films [15]. It is noteworthy that, in most templated sol-gel processes, $\mathrm{WCl}_{6}$ is the most often selected inorganic precursor for tungsten oxide [16].

As an alternative to the widely used, moisture-sensitive and expensive $\mathrm{WCl}_{6}$, the relatively cheap and easy-handled precursor tungstic acid has also been used as precursor to prepare nonporous sol-gel $\mathrm{WO}_{3}$ films for a variety of application $[5,17]$. In many cases, hydrogen peroxide is normally used as a simple complexing agent to form peroxotungstic acid (PTA) in order to stabilise the sol for coating. Among the methods for the preparation of mesostructured tungsten oxide films, a potentiostatic electrodeposition process mediated by surfactants was able to render moderate mesoporosity to tungsten oxide films, which have also shown improved colouration efficiency and colour-bleach kinetics [18, 19].

However, to synthesise mesostructured tungsten oxide films through a surfactant templated sol-gel process remains a challenge due to problems in achieving effective self-assembly and satisfactory mesostructures. Cationic surfactants such as cetyltrimethylammonium chloride (CTAC) and bromide (CTAB) are unsuitable for use as the structure-directing agent with PTA precursor. This is because the cationic surfactant molecules will precipitate Keggin-like PTA polyanions, which prevents the synthesis of a stable coating solution [20]. Furthermore, thermal stability of mesostructured Keggin-surfactant compounds such as $\left(\mathrm{C}_{19} \mathrm{H}_{42} \mathrm{~N}\right)_{6}-\left(\mathrm{H}_{2} \mathrm{~W}_{12} \mathrm{O}_{40}\right)$ is quite poor, which prevents the thermal removal of the template without destroying any obtained mesostructures [20a]. An alternative approach has been reported by Qi and co-workers who prepared mesostructured tungsten oxide films by utilising non-ionic block copolymer as a structure-directing agent. Their approach avoids the instant precipitation of PTA polyanions with cationic surfactant molecules. However, the resulting mesostructures deteriorated rapidly upon heating at $250{ }^{\circ} \mathrm{C}$ and completely collapsed at $300{ }^{\circ} \mathrm{C}$ [21]. To our best knowledge, the use of surfactant templated sol-gel process using tungstic acid precursor, with thermally stable mesostructures allowing calcination at temperatures exceeding $250{ }^{\circ} \mathrm{C}$ has not been achieved or previously reported. 
In this paper, we report a significant development which for the first time allows the use of tungstic acid as precursor for preparation of mesostructured tungsten oxide films via a simple surfactant templated sol-gel deposition process, in which the material exhibits adequate thermal stability to allow the porous structure to be retained even after heat treatment at high temperature $\left(450{ }^{\circ} \mathrm{C}\right)$ to remove the organic template. Thin mesostructured tungsten oxide films can be prepared by this method. The variables that have influence on the mesostructures, including surfactants, heating temperatures and time, have been studied in detail and optimised to produce thermally stable mesostructured $\mathrm{WO}_{3}$ films. XRD has been extensively used to study the mesostructures formed through the self-assembly of surfactants molecules and inorganic species [11, 12, 14, 21-24]. In this work, the mesostructures formed under different conditions during the preparation and heating processes have been studied by XRD.

\section{Experimental}

Tungstic acid ( $\geq 99.0 \%$ ) was bought from Fluka, $\mathrm{H}_{2} \mathrm{O}_{2} 35 \mathrm{wt} . \%$ water solution and the non-ionic surfactant Brij56 $\left(\mathrm{C}_{16} \mathrm{EO}_{10}, \quad \mathrm{C}_{16} \mathrm{H}_{33}\left(\mathrm{OCH}_{2} \mathrm{CH}_{2}\right)_{\mathrm{n}} \mathrm{OH}, \quad \mathrm{n} \sim 10\right)$, $\mathrm{P} 123\left(\mathrm{EG}_{20} \mathrm{PPO}_{70} \mathrm{EG}_{20}, \mathrm{H}\left(\mathrm{OCH}_{2} \mathrm{CH}_{2}\right)_{20}\left(\mathrm{OCH}\left(\mathrm{CH}_{3}\right) \mathrm{CH}_{2}\right)_{70}\left(\mathrm{OCH}_{2} \mathrm{CH}_{2}\right)_{20} \mathrm{OH}\right), \quad$ Brij35 $\left(\mathrm{C}_{12} \mathrm{EO}_{23}, \mathrm{C}_{12} \mathrm{H}_{25}\left(\mathrm{OCH}_{2} \mathrm{CH}_{2}\right)_{\mathrm{n}} \mathrm{OH}, \mathrm{n} \sim 23\right)$ were bought from Aldrich. All the chemicals were used as received.

Peroxopolytungstic acid (PTA) was synthesised through the reaction of $\mathrm{H}_{2} \mathrm{WO}_{4}$ with hydrogen peroxide. Typically, $5.0 \mathrm{~g}$ of $\mathrm{H}_{2} \mathrm{WO}_{4}$ powders were dispersed in $100.0 \mathrm{~g}$ of deionised water, to which $33.0 \mathrm{~g} \mathrm{H}_{2} \mathrm{O}_{2} 35$ wt.\% water solution was added. The reaction mixture was magnetically stirred at $40{ }^{\circ} \mathrm{C}$ overnight to produce a nearly colourless solution. Pale yellow PTA powders were obtained by drying the resultant clear solution at $40{ }^{\circ} \mathrm{C}$ in an oven. To prepare a clear coating sol, $1.0 \mathrm{~g}$ PTA powder was re-dissolved in a mixture of $2.0 \mathrm{~g}$ deionised water and $1.0 \mathrm{~g}$ ethanol. Surfactant solution was prepared by adding the appropriate amount of surfactant to a mixture of $1.25 \mathrm{~g}$ ethanol and $2.5 \mathrm{~g}$ deionised water. A variety of non-ionic surfactants, including P123, Brij35, Brij56, and their mixtures were studied to determine their suitability. In each case, the coating sol was prepared by slowly adding the surfactant solution to the PTA sol prepared as described above under stirring. Pure PTA film was also deposited from sol prepared as above without using any surfactant, as a control. The final PTA weight percentage in the sol was standardised as about 12.9 wt.\% for the different coating sols. The sol was used for dip-coating on cleaned glass substrates at a withdrawal speed of $25 \mathrm{~cm} / \mathrm{min}$ at room temperature. The deposited film was allowed to dry at room temperature for a minimum of 5 minutes and then, the coated glass/film was further thermally treated at temperatures of $100-450{ }^{\circ} \mathrm{C}$ for between 1-20 $\mathrm{h}$ to solidify the film and remove the template. This heat treatment process was carried out in three discrete stages, a lower temperature heat treatment at $100{ }^{\circ} \mathrm{C}$, a 
second higher temperature stage at between $100-300{ }^{\circ} \mathrm{C}$, called intermediate heat treatment, and a third one between $300-450{ }^{\circ} \mathrm{C}$. These heat treatment stages perform different functions as discussed subsequently

XRD measurement was conducted on Siemens D500/D501 with $\mathrm{CuK}_{\alpha}$ radiation $(\lambda=0.1542 \mathrm{~nm})$ at a scanning speed of $0.01^{\circ}$ per second, using low angle diffraction peaks to determine the interpore distances according to the normal Bragg relationship. In this work, the position of the diffraction peaks is reported as a proxy for the interpore distance for simplicity. Accurate estimation of the pore spacing requires the mesostructures to be highly ordered with known geometry. As this could not be confirmed in this case, the results should be considered to provide only an approximation of the mesostructural scale, assuming mesopores are hexagonally arranged analogous to MCM-41 [11].

Thermal analysis was carried out on an ITA-1500 TGA/DSC instrument with heating rate of $10{ }^{\circ} \mathrm{C} / \mathrm{min}$ under normal atmosphere. In all cases, approximately $10 \mathrm{mg}$ samples were used for measurement. Transmission electron microscopy was performed using a Philips CM100 instrument operated at $100 \mathrm{kV}$. Samples for TEM measurement were obtained by scratching off heated film coating from the glass substrates, this being then dispersed in acetone and mounted on copper grids.

\section{Results and discussion}

\subsection{Role of surfactant and solvent on mesostructures formation and stability}

In these experiments, the surfactants P123, Brij56 and a surfactant mixture of Brij35 and P123 with weight ratio of Brij35 to P123 of 1:3 (designated BP) were investigated as potential templates for mesostructured films from the PTA sol-gel route.

In each case, the tungsten oxide-surfactant hybrid coatings were all optically transparent after drying at room temperature, irrespective of the PTA to surfactant weight ratios. The dried films were then subjected to a two or 3 stage heat treatment with the time and temperatures shown inset in the figure captions for Fig. 1a $-\mathrm{f}$, and studied by low angle XRD to determine the order and scale present in the mesostructures, with the corresponding results shown in these figures.

The system studied in Fig.1a is similar to that previously reported by Qi and co-workers [21] with the same P123 surfactant. However, in this case the weight ratio of PTA to P123 (designated as $\mathrm{m}(\mathrm{PTA})$ : $\mathrm{m}(\mathrm{P} 123)$ ) is $4: 1$, compared to the much higher level of surfactant in that work $(\mathrm{m}(\mathrm{PTA}): \mathrm{m}(\mathrm{P} 123)=2.8: 1[21])$. In this case the obtained low angle peak is considerably less distinct, indicating less ordering of the mesostructures. This is consistent with the reduced surfactant levels. However, interestingly, compared with results reported by Qi and co-workers, it shows slightly 
improved thermal stability. It can be seen that the low angle XRD peak, although quite small, is still observable for this sample even after heating to $300{ }^{\circ} \mathrm{C}$.

P123 is a tri-block copolymer of the form PEG-PPO-PEG. It has been demonstrated that there are strong interactions between tungstic acid groups with PEG species via hydrogen-bonding [2b]. In our system, not only do such interactions promote the self-assembly process, which is responsible for the formation of mesophases in the coating, but also lead to the formation of quite flexible hybrid frameworks. Hence, the more rigid and robust frameworks which would be anticipated with presence of a smaller amount of P123 are very important for the formation of stable mesostructures, which will undergo smaller changes upon heating at elevated temperatures. However, even at this lower level of surfactant addition it can be seen that the resultant materials can still not withstand heating to a temperature of $400{ }^{\circ} \mathrm{C}$ (Fig.1a, curve 3 ).
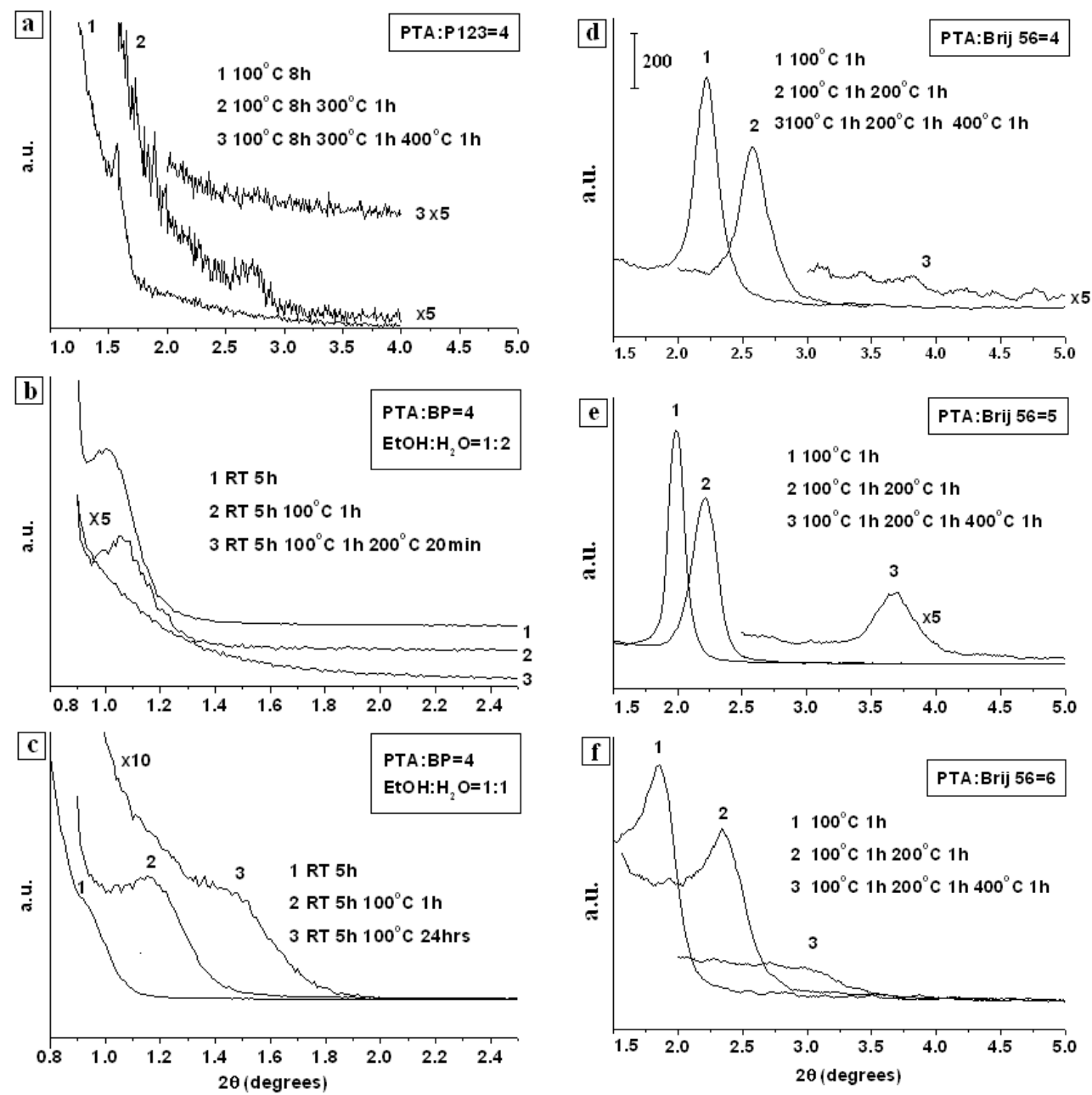

Fig. 1 XRD patterns of (a) PTA/P123 films heated at different temperatures (m(PTA) : $\mathrm{m}(\mathrm{P} 123)=4)$. (b) PTA/BP (m(PTA): $\mathrm{m}(\mathrm{BP})=4)$ films heated at different temperatures. (c) PTA/BP $(\mathrm{m}(\mathrm{PTA}): \mathrm{m}(\mathrm{BP})=4)$ films heated at different temperatures and ethanol to de-ionized water weight ratios in the sols set to 1:1 (if not indicated otherwise, ethanol to deionised water weight ratios in the sols are always set to 1:2). (d), (e) and (f) show PTA/Brij56 films heated at different temperatures coated using sols with different $\mathrm{m}(\mathrm{PTA})$ to $\mathrm{m}$ (Brij56) of 4, 5 and 6 , respectively. 
Considering the role of the solvent, P123 with blocks of polypropylene oxide and polyethylene glycol (PEG) is a good surfactant in acidic aqueous solutions. Such behaviour is due to the hydrophobic nature of polypropylene oxide (PPO) while polyethylene glycol remains hydrophilic. However, this difference in hydrophilicity becomes less prominent in a more ethanolic solution because ethanol is a good solvent for both segments. However, in the case of the peroxotungstic acid sol used in this case, the presence of ethanol is necessary to stabilise the sol against gelation. Thus it is reasonable to assume that P123 is not an ideal template for this system.

With the aim to mitigate this problem, a surfactant blend of Brij35 with P123 ( $m($ Brij35): $m(P 123)=3: 1)$ was chosen to enhance the hydrophilic and hydrophobic contrast. Such a strategy has been shown to be advantageous in synthesising mesoporous silica in non-aqueous solvent [22]. As shown in Fig.1b, the low-angle reflections increase upon the addition of Brij35, confirming the formation of better defined mesostructures compared to those obtained from the pure P123 surfactant. However, the thermal stability is not correspondingly improved. It can be observed that the low-angle XRD peak disappeared completely for this system upon heating at $200{ }^{\circ} \mathrm{C}$. Additionally, in the system studied in Fig.1c, the level of ethanol present in the coating sol is increased from $1: 2$ to $1: 1$ in terms of $m\left(\right.$ ethanol): $m\left(\mathrm{H}_{2} \mathrm{O}\right)$. The results confirm that the presence of increased ethanol results in even less-ordered structures.

In both of the above systems, further decrease in surfactant content in m(PTA):m(BP) from 4:1 shown in Fig. 1(c) to 5:1 (XRD patterns not shown here) led to corresponding reductions in the structure directing effect, with nearly undetectable low angle XRD peaks. However conversely, the thermal stability of these mesostructures was slightly improved, these being stable upon heating at $300{ }^{\circ} \mathrm{C}$ for either P123 or BP template.

Unfortunately, for both the above surfactant systems and irrespective of the surfactant levels, heat treatment at $400{ }^{\circ} \mathrm{C}$ led to nearly complete collapse of the mesostructures. It is believed that in the template molecules of P123 or P123/Brij35, the long and branched EO segments favour the formation of very flexible hybrid frameworks in which these groups are incorporated into the oxide framework walls, with this flexibility allowing degradation of the structure during heating and hence responsible for the poor thermal stability of the obtained mesostructures. It is thus necessary to find a more suitable template in order to improve the ordering of the mesostructures and thermal stability. According to the above proposition, a template that contains a hydrophobic chain and shorter hydrophilic EO segment than those in P123 and Brij35 might be advantageous for the formation of both the desired mesostructures and good thermal stability. In order to test this, the surfactant, Brij56, in which the EO segment is halved in length compared with the previous surfactants, was selected. The results 
shown in Fig.1d, e and f, were obtained from this surfactant system at different levels of surfactant (m(PTA): m(Brij56) between 4 and 6).

From observation of these figures, it is apparent that in all cases, the low-angle XRD peaks are much more intense and distinct than those obtained using P123 or BP surfactant systems. XRD analysis of these films before heat treatment (after drying at room temperature), show even more intensive peak centred at about $1.5^{\circ}$, corresponding to a pore-pore repeat distance of about $6.8 \mathrm{~nm}$ (XRD patterns not shown here). The calculated $d_{100}$ (about $5.9 \mathrm{~nm}$ ) is also quite consistent with values reported for mesoporous silica using the same template [23], implying a similar template mechanism applies for PTA polyanions in association with Brij56 template.

After heat treatment of the film at $100{ }^{\circ} \mathrm{C}$ for $1 \mathrm{~h}$ (Fig.1e) with the aim to remove the ethanol and physically adsorbed water, the XRD pattern remains strong and distinct although shifted slightly. The calculated $\mathrm{d}_{100}$ is reduced to about $4.8 \mathrm{~nm}$. Only one intense peak, indexed as (100), is present indicating the hybrid film has mesostructures lacking long-range ordering.

As can be seen from Fig.1d, e, and f, the respective weight ratio of PTA to Brij56 surfactant also plays an important role in both the mesostructure ordering and the thermal stability of PTA/Brij56 hybrid coatings. It can be seen (Fig.1f) that reduced amounts of template (m(PTA): $\mathrm{m}($ Brij56) $=6$, Fig.1f) leads to broadened low-angle XRD peaks, corresponding to the formation of even less-ordered mesostructures. Higher amounts (Fig.1d) of Brij56 (m(PTA): m(Brij56)=4), however, leads to more flexible framework walls and impaired thermal stability, evidenced by the more significant low-angle peak shifts to higher position and the broadening to give larger FWHH (Full Width at the Half-Height) (Table 1) after heating at $200{ }^{\circ} \mathrm{C}$, while the peak disappears after heating to $400{ }^{\circ} \mathrm{C}$. A weight ratio of PTA to Brij56 of 5:1, however, yielded the most thermally stable and ordered mesostructures (Fig. 1e). In this case, the low-angle XRD peak is still observable even after heating to $400{ }^{\circ} \mathrm{C}$, although it broadens from $0.13^{\circ}$ to $0.33^{\circ}$ in FWHH (Table 1).

The above results appear to confirm the mechanism proposed for the thermal instability of the earlier surfactant systems. The results confirm that the more PEG segments which are introduced into the hybrid frameworks, the more flexible resultant mesostructures, and the worse the thermal stability of the obtained materials. By contrast, the use of surfactants with shorter EO segments in Brij56 results in more thermally stable hybrid films.

In conclusion, of the various surfactant systems (Brij56, P123 and Brij35/ P123 (BP)) studied, the former produced the best mesoporous structures. Upon calcination at elevated temperatures $\left(400{ }^{\circ} \mathrm{C}\right)$, the best thermal stability was obtained when m(PTA): $\mathrm{m}$ (Brij56) was 5 (All work below is based on this weight ratio). By contrast, 
decreasing the amounts of P123 or BP did not result in satisfactory improvements in the thermal stabilities of the mesostructures (results not shown here). The rest of this paper is therefore focused on Brij56 templated tungsten oxide films.

Table 1 Two-theta values in low-angle XRD pattern shown in Fig. 1d, e and f.

\begin{tabular}{llcc}
\hline $\begin{array}{c}\text { Heating } \\
\text { temperatures }\end{array}$ & \multicolumn{4}{l}{ PTA:Brij56 (weight ratios) } \\
\cline { 2 - 4 } $100{ }^{\circ} \mathrm{C}$ & $2.22(0.20)$ & $1.99(0.13)$ & 6 \\
$200{ }^{\circ} \mathrm{C}$ & $2.58(0.25)$ & $2.22(0.20)$ & $2.33(0.24)$ \\
$400{ }^{\circ} \mathrm{C}$ & -- & $3.67(0.33)$ & $2.91(0.72)$
\end{tabular}

Note: Values in brackets correspond to FWHHs of the XRD peaks.

\subsection{Influence of heat treatment process on mesostructure formation and stability}

The influence of heating on the mesostructures was further investigated. Fig.2A and B show the relationship of the low-angle peak position with the heating time for samples heated at $100{ }^{\circ} \mathrm{C}$. It can be seen from this figure that the diffraction peak gradually shifts to higher angles from about $1.9^{\circ}$ to $2.2^{\circ}$ with increasing heating time up to $30 \mathrm{~h}$ at $100{ }^{\circ} \mathrm{C}$. However the intensity remains essentially constant during heating, suggesting that mesostructures undergo reorganisation but do not deteriorate much upon heating to this temperature. This is understandable because the template would be expected to remain intact at this temperature but with shrinkage in the framework walls occurring due to gradual decomposition of PTA (see detail below in thermal analysis).
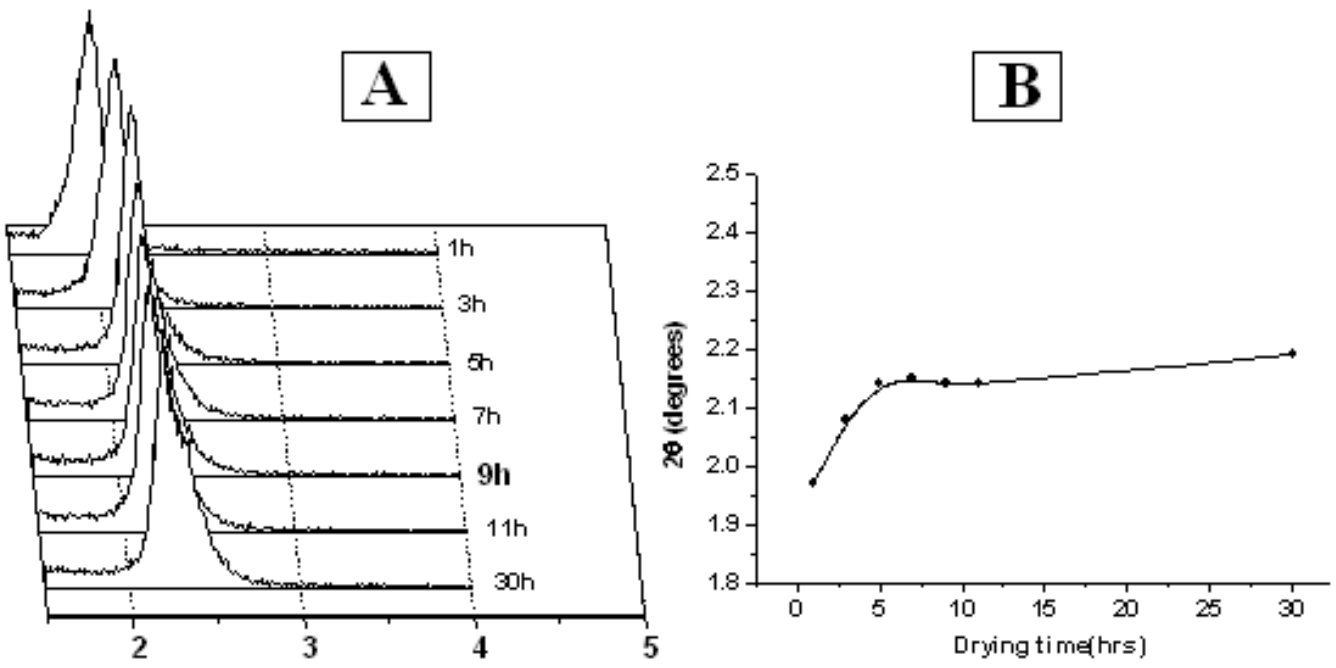

Fig. 2 (A) XRD patterns of PTA/hybrid films heated at $100{ }^{\circ} \mathrm{C}$ for varying time $(\mathrm{m}(\mathrm{PTA}): \mathrm{m}(\mathrm{Brij} 56)=5)$ and (B) the evolution of $2 \theta$ values as function of heating time derived from (A). 
It is well known, from extensive studies of sol-gel derived mesoporous silica, that suitable control on the hydrolysis and condensation is necessary to synthesise good mesostructures $[11,12]$. The condensation step in the sol-gel process is normally incomplete in as-deposited films, and usually requires an appropriate heat treatment [11] to facilitate. Therefore, besides the selection of suitable template in terms of specific inorganic precursor, appropriate control of the heat treatment conditions is necessary to achieve mesostructures with the best thermal stability.

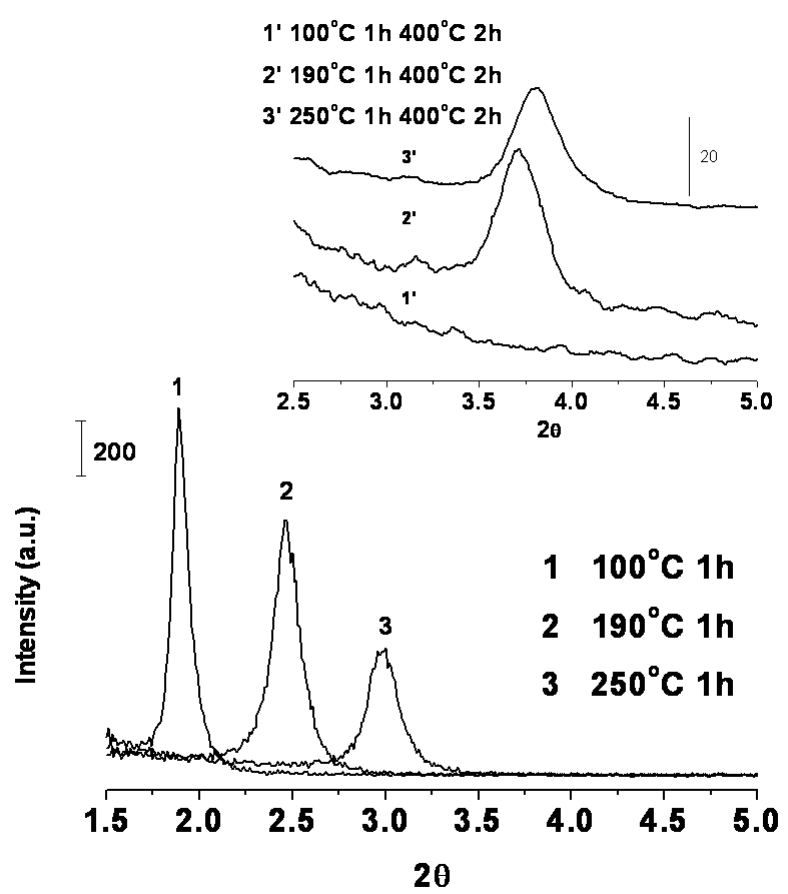

Fig.3 XRD patterns showing the influence of heat treatment on the structure of PTA/Brij56 (m(PTA) :m(Brij56=5) hybrid films.

In the majority of these experiments, a three stage heat treatment process was used, comprising an initial heat treatment at $100{ }^{\circ} \mathrm{C}$, an intermediate heat treatment at between $100{ }^{\circ} \mathrm{C}$ and $300{ }^{\circ} \mathrm{C}$, followed by a final stage heat treatment at $400{ }^{\circ} \mathrm{C}$ or higher temperatures. For comparison purposes, a single stage heat treatment comprising direct heating to $400{ }^{\circ} \mathrm{C}$ was also used for some samples. Fig. 3 shows the influence of these various heating conditions on the low angle XRD peaks and hence mesostructures of PTA/Brij56 hybrid films.

Direct calcination of the films at $400{ }^{\circ} \mathrm{C}$ led to the collapse of mesostructures, with no observable XRD peak present (not shown). Similar results were obtained when the films were pre-heated to $100{ }^{\circ} \mathrm{C}$ (Fig.3, curve 1 and 1 '). However, by employing an appropriate intermediate heat treatment stage at temperatures, such as 190 (Fig.3, curve 2 and $2^{\prime}$ ) and $250{ }^{\circ} \mathrm{C}$ (Fig.3, curve 3 and $3^{\prime}$ ), we have determined that it is 
possible to obtain a material which retains its mesostructure even after subsequent heating to $400{ }^{\circ} \mathrm{C}$.

In comparison with previous reported studies of mesoporous tungsten oxide, this represents a significant advance. For example, in the case of previous reports of non-ionic surfactant templated sol-gel processes using the same PTA precursor [21], the obtained structures were found to be unstable against heating at $300{ }^{\circ} \mathrm{C}$, resulting in collapse of the mesostructures. Similarly, even using $\mathrm{WCl}_{6}$ as tungsten precursor $[15,24]$, the structures were not capable of withstanding heat treatment at temperatures as high as $400{ }^{\circ} \mathrm{C}$, although $\mathrm{WCl}_{6}$ is believed to be more capable of cross-linking in the framework walls via hydrolysis and condensation reactions compared with PTA species [20, 21, 24]. In this work, however, by careful selection of suitable non-ionic surfactant and heating processes, thermally stable mesostructured tungsten oxide film can be obtained from PTA/Brij56 sol, capable of withstanding heat treatment at $400{ }^{\circ} \mathrm{C}$.

In addition to the increase in thermal stability, there is evidence that, reorganization of the meso-frameworks also occurs during heat treatment of the materials obtained by this new route. As shown in Fig. 3, the low-angle XRD peak shifts with an increase of the intermediate heat treatment temperatures from $100^{\circ} \mathrm{C}\left(2 \theta \approx 1.9^{\circ}\right)$ to $190{ }^{\circ} \mathrm{C}(2 \theta \approx 2.5$ $\left.{ }^{\circ}\right)$ and $250^{\circ} \mathrm{C}\left(2 \theta \approx 3.0^{\circ}\right)$. Such changes suggest that the resultant hybrid film after heating to these temperatures is flexible, allowing the pore spacing to change without seriously disrupting the ordered mesostructures, although the intensity does decrease somewhat particularly for the higher of these intermediate heat treatment temperatures. This contrasts with results obtained for $\mathrm{WCl}_{6}$ derived sol-gel mesostructured film. As reported by Yuan and co-workers, such sol-gel film templated by non-ionic surfactant TMDD using $\mathrm{WCl}_{6}$ resulted in vermicular mesostructures after removal of the template by heating at $300{ }^{\circ} \mathrm{C}$, with the mesostructures completely disappearing after heating to $400{ }^{\circ} \mathrm{C}$. Significantly little peak shift was reported in that work upon heating at $300{ }^{\circ} \mathrm{C}$ [24], indicating less flexibility of the structure. In comparison with the PTA/Brij56 hybrid reported here, hydrolysis and condensation of $\mathrm{WCl}_{6}$ took place before and/or after coating, which promoted the cross-linking between tungsten oxide species and consolidation of the film, resulting in a structure rigid enough to sustain heating to $300{ }^{\circ} \mathrm{C}$. However, in many reports, inappropriate organic template and improperly optimised heating treatment led to worse thermal stability $\left(<400{ }^{\circ} \mathrm{C}\right)$ of resultant mesostructured tungsten oxide $[14,21,24]$ than those derived from our PTA/Brij56 system.

\subsection{Further optimisation of the heating conditions}

It has been reported that interaction of PEG with tungstic acid species significantly retards the crystallisation of tungsten oxide [25]. Therefore, it is believed that the cross-linking of tungsten oxide species via the condensation reaction would be 
obstructed by the presence of PEG groups. Thus in order to achieve even more stable mesostructures, it was postulated that further optimisation of the intermediate heat treatment conditions, in particular balancing the competing effects of the increased condensation against the removal of the organic template and associated complexing effects of the PEG with the tungsten species as a function of increased time and temperature for the intermediate heat treatment step, would be a promising approach.
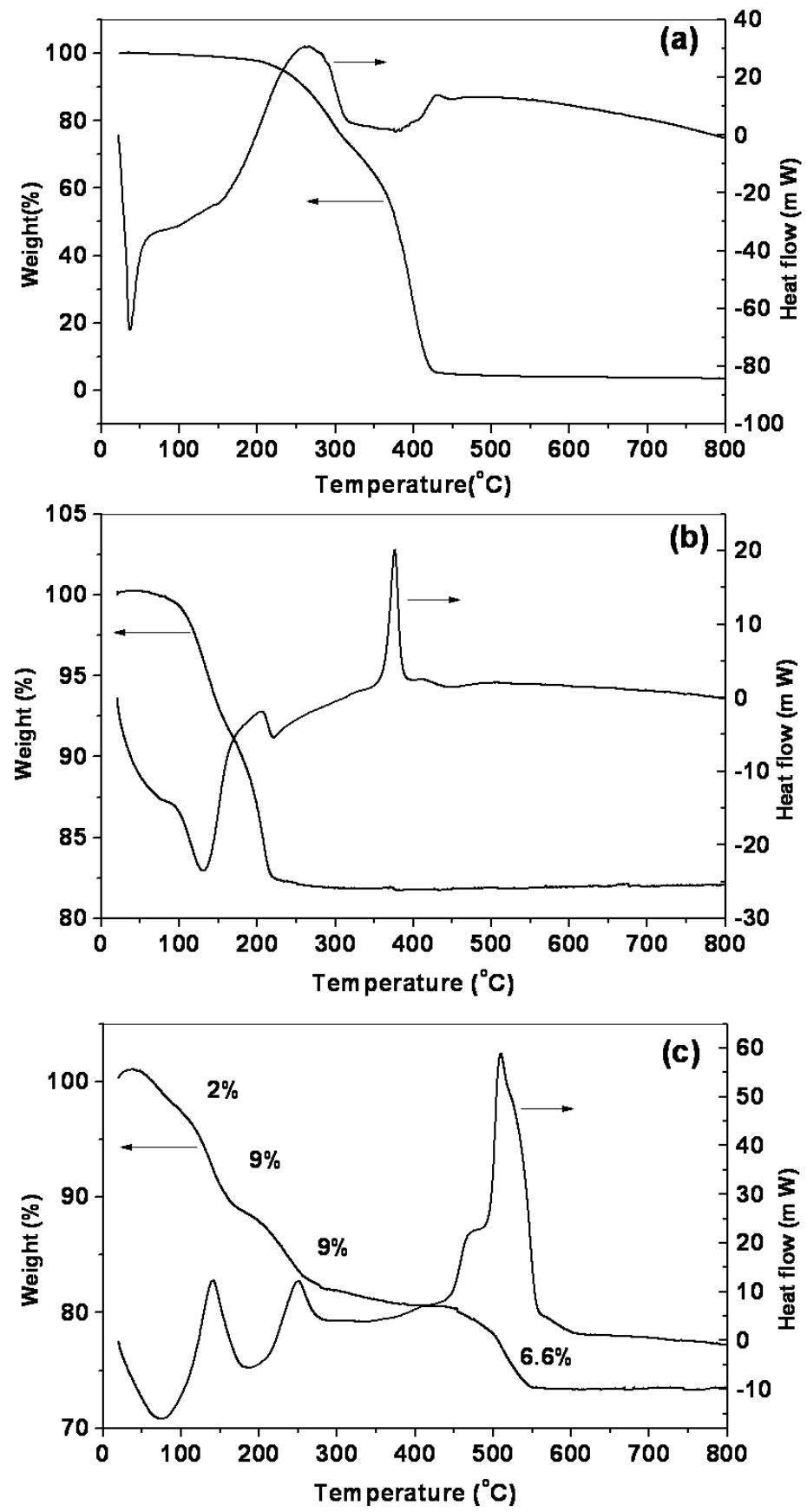

Fig. 4 TGA/DSC curves for (a) Brij56, (b) PTA, (c) PTA/Brij56 (m(PTA) :m(Brij56)=5:1) sol-gel film dried at room temperature for 3 days.

In order to further improve the thermal stability of PTA/Brij56 hybrid films, it is 
necessary to study the chemical or physical changes taking place during the heating process. TGA/DSC experiments were therefore carried out. From Fig.4 (a), Brij56 melts at about $37^{\circ} \mathrm{C}$ and starts to decompose at around $200{ }^{\circ} \mathrm{C}$. For pure PTA (Fig.4b), TG shows about $20 \%$ of the total weight loss occurs on heating up to $250{ }^{\circ} \mathrm{C}$. Correspondingly, an endothermic peak at about $130{ }^{\circ} \mathrm{C}$ of the DSC corresponds to decomposition of peroxotungsten groups, and a small endotherm at about $220{ }^{\circ} \mathrm{C}$ can be ascribed to the loss of structural water by condensation reaction of $\mathrm{W}-\mathrm{OH}$ groups [26]. Additionally, pure PTA was transformed into crystalline $\mathrm{WO}_{3}$ at about $375{ }^{\circ} \mathrm{C}$, from which one very sharp peak can be seen (Fig. 4b). This correlates with previously reported results [4c]. Fig.4c shows the TGA/DSC curves for PTA/Brij56 (1:5) powders obtained by drying the sol at room temperature for three days. It can be seen from Fig. 4c that two broad endothermic peaks centre at around $90{ }^{\circ} \mathrm{C}$ and $185{ }^{\circ} \mathrm{C}$, respectively. The first is due to the liberation of adsorbed water and following decomposition of PTA groups. The second one can be ascribed to two parallel processes: the partial decomposition of the Brij56 organic template and the condensation of $\mathrm{W}-\mathrm{OH}$ groups. The shoulder at about $440{ }^{\circ} \mathrm{C}$ indicates the initiation of crystallisation of tungsten oxide and is consistent with results reported elsewhere [25]. The decomposition of Brij56 and further release of water by condensation reaction before $300{ }^{\circ} \mathrm{C}$ constitute around $70 \%$ of the total weight loss and appear to corroborate the supposition above that heating at intermediate temperatures, such 190 ${ }^{\circ} \mathrm{C}$ or $250{ }^{\circ} \mathrm{C}$ promotes further condensation of $\mathrm{W}-\mathrm{OH}$ groups, facilitating the consolidation and stabilisation of the mesostructures of PTA/Brij56 hybrids against subsequent higher temperature heat treatment.

To further test this, a number of alternative thermal treatments were investigated. Fig. 5 shows the XRD patterns of PTA/Brij56 hybrid films heated at temperatures up to $450{ }^{\circ} \mathrm{C}$ at intermediate heating temperature of $250{ }^{\circ} \mathrm{C}$. Where the intermediate heat treatment time at $250^{\circ} \mathrm{C}$ was either too long (e.g. 20 h, Fig.5, curves 7-9) or too short (e.g. 1h, see Fig.5, curves 1-3) at $250{ }^{\circ} \mathrm{C}$, it is not possible to obtain a well preserved mesostructured material. This can be explained as follows:

In the case of films heat treated at $250{ }^{\circ} \mathrm{C}$ for $1 \mathrm{~h}$ or less, the mesostructures is well retained during this heat treatment stage. However the structure is essentially completely degraded after subsequent exposure to higher temperatures $\left(450{ }^{\circ} \mathrm{C}\right)$. This can be explained as being due to the condensation reactions in the tungsten oxide framework being insufficient to give the structure sufficient coherency to withstand the subsequent high temperature heat treatment. For films heat treated at $250{ }^{\circ} \mathrm{C}$ for a long period (e.g. $20 \mathrm{~h}$ ), the mesostructures deteriorates during the heat treatment, evidenced by the reduction in intensity of the low angle XRD peak at circa $2.75^{\circ}$ At the same time, the appearance changes during heat treatment, becoming visibly less brown and more transparent, suggesting the organic template is gradually decomposed and removed. This has been confirmed by the TGA/DSC results (not shown here). 
According to the TGA/DSC results (Fig.4a), decomposition of the organic template commences at temperatures of approximately $200{ }^{\circ} \mathrm{C}$. However, the presence of the organic template within the material is believed to be significant in the stabilisation of the mesostructures upon calcination at higher temperatures. It has been reported in other work that the presence of the thermally stable surfactant "KLE" enables the formation of thermally stable mesostructures [16e]. In the case of the Brij56 surfactant used here, decomposition of the surfactant would be expected to occur at lower temperatures, but with the extent of this being a function of heat treatment time and temperature. Moreover, organic groups also play an important role in restricting the crystallisation of tungsten oxide, mitigating the mass transport happening otherwise and hence helping stabilising the frameworks. Thus where the surfactant survives the intermediate heat treatment step, a proportion of this is expected to be temporarily retained even during heat treatment at higher temperatures provided the exposure time is limited.
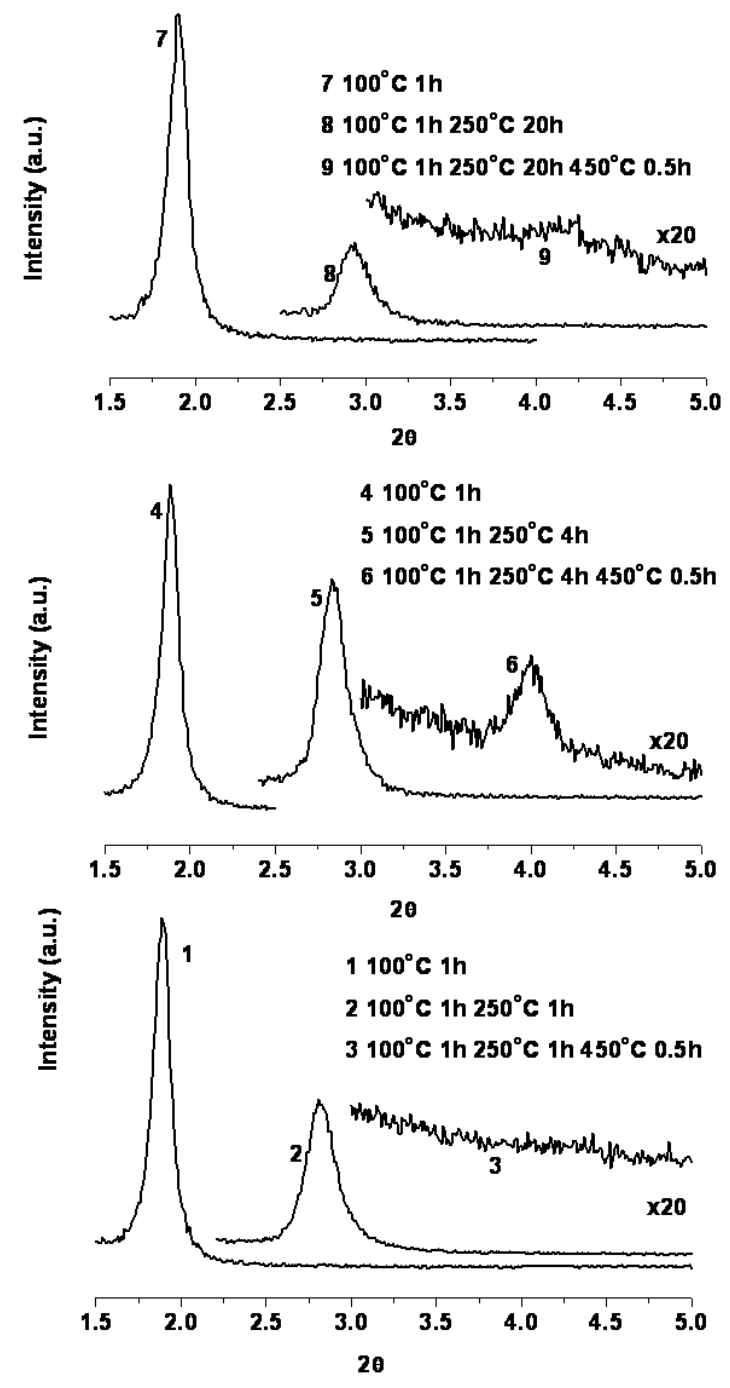

Fig.5 XRD patterns for PTA/Brij56 (m(PTA): $\mathrm{m}($ Brij56)=5) hybrid films heated via different routes at optimizing the thermal stability of mesostructures. 
Therefore, in order to obtain the best thermal stability and mesostructures, the time and temperature of the intermediate heat treatment step needs to be optimised to balance the competing effects of (I) the increase in extent of the condensation reaction and, (II) the increasing decomposition of the organic template, which both occur with increased time and temperatures. As shown in Fig.5 ( $5^{\text {th }}$ and 6th curve), the best conditions for obtaining the most stable mesostructures in PTA/Brij56 hybrid films involve an intermediate heat treatment at $250{ }^{\circ} \mathrm{C}$ for $4 \mathrm{~h}$ prior to the high temperature $\left(450{ }^{\circ} \mathrm{C}\right)$ exposure.

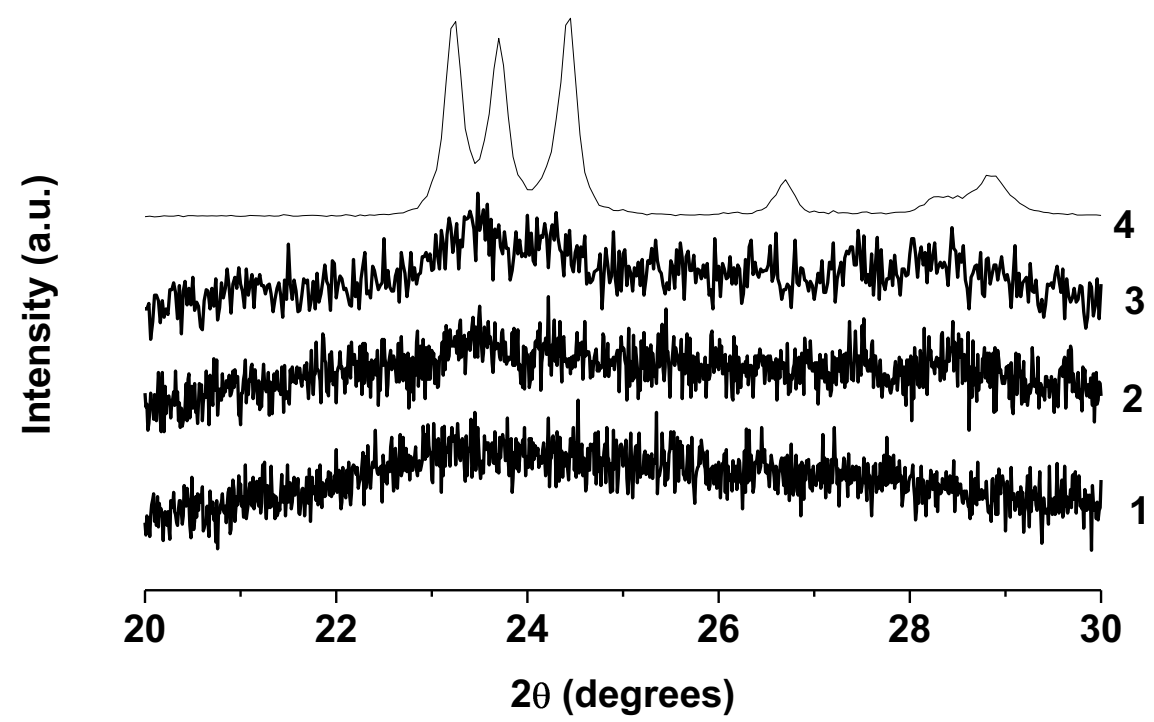

Fig.6 Wide-angle XRD patterns for (1) PTA/Brij56 (m(PTA):m(Brij56)=5) hybrid films calcined at 450 ${ }^{\circ} \mathrm{C}$ for $0.5 \mathrm{~h}$, (2) PTA/Brij56 (m(PTA):m(Brij56)=5) hybrid films calcined at $450{ }^{\circ} \mathrm{C}$ for $2 \mathrm{~h}$, (3) Pure PTA film coated on glass heated at $400{ }^{\circ} \mathrm{C}$ for $1 \mathrm{~h}$. (4) Bulk monoclinic crystalline $\mathrm{WO}_{3}$ heated at 500 ${ }^{\circ} \mathrm{C}$ for $2 \mathrm{~h}$ as reference.

It is worth mentioning that in all cases, calcination at $450{ }^{\circ} \mathrm{C}$ for $1 \mathrm{~h}$ or longer or at higher temperatures than $450{ }^{\circ} \mathrm{C}$ leads to complete disappearance of the low-angle XRD peaks (XRD patterns not shown here), indicating the collapse of mesostructures. However the resultant tungsten oxide film remains essentially X-ray amorphous even after heat treatment at $450{ }^{\circ} \mathrm{C}$ for up to $2 \mathrm{~h}$ (Fig.6, curves $1 \& 2$ ). By comparison, the results obtained for a similar film derived from the PTA but without the addition of the surfactant (Fig. 6, curve 3) indicate the commencement of crystallisation at temperatures as low as $400{ }^{\circ} \mathrm{C}$. These results confirm the stabilising effect of the surfactant against crystallisation of the tungsten oxide as described above.

Additionally, as shown in Fig. 5 (and also Fig. 1e), where mesoporous structures are retained, the low-angle XRD peaks for samples heated at temperatures higher than $250{ }^{\circ} \mathrm{C}$ are generally shifted to higher angles, typically ranging from $\approx 3^{\circ}$ to $\approx 4{ }^{\circ}$, indicating that the porous structure might have fallen into the microscopic regime. 
More investigations are undergoing to investigate in more detail the mechanisms of the pore structure transformation as a function of the calcination conditions.

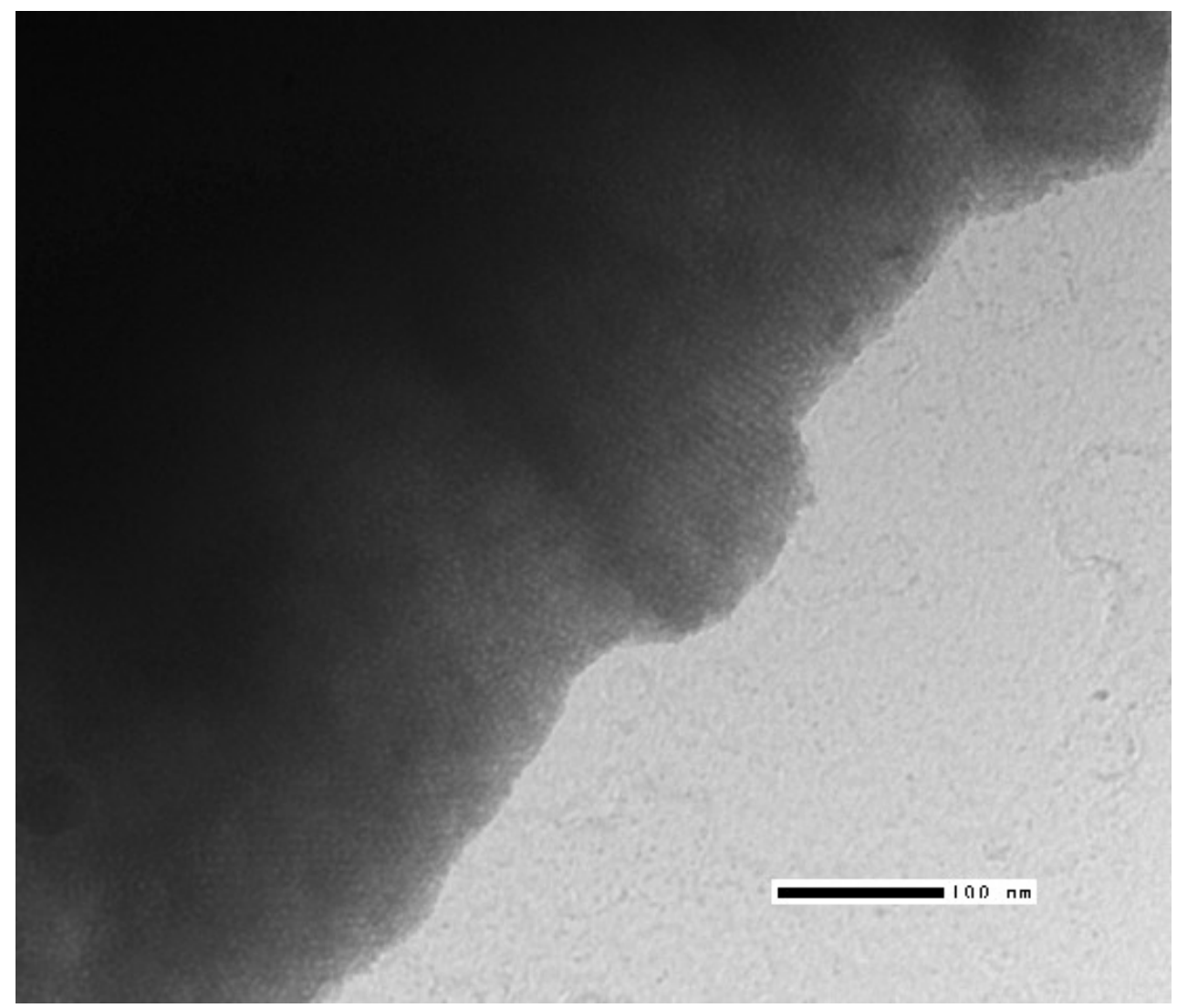

Fig.7 TEM micrograph of PTA/Brij56 (m(PTA):m(Brij56)=5) hybrid films heated at $100{ }^{\circ} \mathrm{C}$ for $1 \mathrm{~h}$ (scale bar is $100 \mathrm{~nm}$ ).

The focus of these investigations was primarily on the use of the low-angle XRD technique to examine and monitor mesostructures. However, TEM results (Fig.7) also confirmed the existence of mesostructures. For example, for the sample dried at 100 ${ }^{\circ} \mathrm{C}$, this TEM image shows quite ordered mesophases with interpore distance of about $6 \mathrm{~nm}$ and tungsten oxide wall of about $2.5 \mathrm{~nm}$ (pore size is about $3.5 \mathrm{~nm}$ ). Such results are in good accordance with the XRD results $\left(2 \mathrm{~d}_{100} / \sqrt{3}=5.4 \mathrm{~nm}\right)$ and those in ref. [23]. It also can be seen from TEM images that the pore channels lie perpendicular to the substrate which allows access to the pore from above. SEM results (not shown here) also showed that the thickness of film heated at $400{ }^{\circ} \mathrm{C}$ for $2 \mathrm{~h}$ was about $200 \mathrm{~nm}$. Physisorption measurement would provide additional information, but the strong adherence of the films to the substrate has prevented obtaining suitable samples to analyse and further work is needed in this regard. However, an estimated BET surface area of around $250 \mathrm{~m}^{2} / \mathrm{g}$ can be inferred for the tungsten oxide film dried at $100{ }^{\circ} \mathrm{C}$ (assuming no template in pore region) based on the BET surface area of mesoporous silica synthesised by using the same template and with comparable mesostructures ( $d$ $\left.\left(\mathrm{SiO}_{2}\right)=2.2 \mathrm{~g} / \mathrm{cm}^{3}\right)$ to our mesoporous tungsten oxide $\left(\mathrm{d}\left(\mathrm{WO}_{3}\right)=7.16 \mathrm{~g} / \mathrm{cm}^{3}\right)$ films [23]. 


\section{Conclusion}

By choosing suitable organic template and optimisation of the process conditions, it has for the first time been demonstrated that tungstic acid can be successfully used as inorganic precursor to synthesise thermally stable mesostructured tungsten oxide films obtained by a surfactant templated sol-gel dip-coating process on glass substrate. Of the surfactant systems trialled, Brij56 was found to be the most successful to template the peroxotungstic acid in the water/ethanol mixtures. A multi-stage heat treatment is required to balance the requirement to effect the sol-gel condensation reaction against the removal of the organic species allowing the formation of mesostructures, which can be retained even after calcination at temperatures up to $450{ }^{\circ} \mathrm{C}$. Electrochromic properties of these materials have been tested and yielded excellent results, which will be reported in detail in a subsequent publication

\section{References:}

[1] H. Habazaki, Y. Hayashi, H. Konno, Electrochim. Acta, 47 (2002) 4181.

[2] (a) H. Wang, T. Lindgren, J. He, A. Hagfeldt, S. E. Lindquist, J. Phys. Chem. B, 104 (2000) 5686. (b) C. Santato, M. Ulmann, J. Augustynski, J. Phys. Chem. B 105 (2001) 936; (c) C. Santato, M. Odziemkowski, M. Ulmann, J. Augustynski, J. Am. Chem. Soc. 123 (2001) 10639. (d) S. Berger, H. Tsuchiya, A. Ghicov, P. Schmuki, Appl. Phys. Lett. 88 (2006) 203119.

[3] (a) C. Cantalini, L. Lozzi, M. Passacantando, S. Santucci, IEEE Sens. J., 3 (2003) 171. (b) J. Tamaki, Y. Okochi, S. Konishi, Electrochemistry 74 (2006) 159.

[4] (a) C. G. Granqvist, Sol. Energy Mater. Sol. Cells, 60 (2000) 201. (b) J. Livage, D. Ganguli, Sol. Energy Mater. Sol. Cells 68 (2001) 365. (c) A. Patra, K. Auddy, D. Ganguli, J. Livage, , P. K. Biswas, Mater. Lett. 58 (2004) 1059.

[5] (a) B. Munro, S. Kramer, P. Zapp, H. Drug, J. Sol-Gel Sci. Technol., 13 (1998) 673. (b) L. Zhuang, X. Xu, H. Shen, Surf. Coat. Technol. 167 (2003) 217. (c) G. Leftheriotis, S. Papaefthimiou, P. Yianoulis, A. Siokou, D. Kefalas, Appl. Surf. Sci. 218 (2003) 275. (d) M. Deepa, R. Sharma, A. Basu, S. A. Agnihotry, Electrochim. Acta, 50 (2005) 3545.

[6] A. Rougier, F. Portemer, A. Quédé, M. El Marssi, Appl. Surf. Sci. 153 (1999) 1.

[7] A. Dipaola, F. Diquarto. C. Sunseri, J. Electrochem. Soc. 125 (1978) 1344.

[8] (a) L. Meda, R. C. Breitkopf, T. E. Haas, R. U. Kirss, Thin Solid Films, 402 (2002) 126; b) M. Regragui, M. Addou, A. Outzourhit, Thin Solid Films, 358 (2000) 40.

[9] (a) S. H. Baeck, T. Jaramillo, G. D. Stucky, E. W. McFarland, Nano Lett. 2 (2002) 831; (b) S. H. Baeck, K. S. Choi, T. F. Jaramillo, G. D. Stucky, E. W. McFarland, Adv. Mater. 15 (2003) 1269; (c) S. H. Baeck, T. F. Jaramillo, C. Brandli, E. W. McFarland, J. Comb. Chem., 4 (2002) 563. (d) E. A. Meulenkamp, J. Electrochem., 144 (1997) 1664. (e) B. Yang, H. J. Li, M. Blackford, V. Luca, Curr. Appl. Phys. 6 (2006) 436. (f) C. Cantalini, M. Pelino, H.T. Sun, M. Faccio, S. Santucci, L. Lozzi, M. Passacantando, Sensors Actuat. B 35-36 (1996) 112.

[10] (a) A. P. Baker, S. N. B. Hodgson, M. J. Edirisinghe, Surf. Coat, Technol. 153 (2002) 184. (b) V. Guidi, M. Blo, M. A. Butturi, M. C. Carotta, S. Galliera, A. Giberti, C. Malagù, G. Martinelli, M. Piga, M. Sacerdoti, B. Vendemiati, Sensors Actuat. B 100 (2004) 277. (c) S. Badilescu, P. V. Ashrit, Solid State Ionics 158 (2003) 187. (d) M. Tong, G. Dai, D. Gao, Mater. Chem. Phys. 69 (2001) 176. 
[11] (a) C. T. Kresge, M. E. Leonowicz, W. J. Roth, J. C. Vartuli, J. S. Beck, Nature 359 (1992) 710.(b) J. S. Beck, J. C. Vartuli,W. J. Roth, M. E. Leonowicz, C. T. Kresge, K. D. Schmitt, C. T.-W. Chu, D. H. Olson, E. W. Sheppard, S. B. McCullen, J. B. Higgins, J. L. Schlenkert, J. Am. Chem. Soc. 114 (1992) 10834.

[12] (a) W. Wang, M. Song, Micro. Meso. Mater. 96 (2006) 255. (b)W. Wang, M. Song, Mater. Res. Bull. 41 (2006) 436. (c) W. Wang, M. Song, Mater. Res. Bull. 40 (2005) 1737.

[13] (a) M. Grätzel, Nature 409 (2001) 575. (b)C. Bechinger, E. Wirth, P. Leiderer, Appl. Phys. Lett. 68 (1996) 2834.

[14] (a) P. Yang, D. Zhao, D. I. Margolese, B. F. Chmelka, G. D. Stucky, Chem Mater. 11 (1999) 2813. (b) P. Yang, D. Zhao, D. I. Margolese, B. F. Chmelka, G. D. Stucky, Nature 396 (1998)152.

[15] W. Cheng, E. Baudrin, B. Dunn, J. I. Zink, J. Mater. Chem. 11 (2001) 92.

[16] (a) W. H. Lai, J. Shieh, L. G. Teoh, I. M. Hung, C. S. Liao, M. H. Hon, J. Alloy. Compd., 396 (2005) 295. (b) We. H. Lai , L. G. Teoh, Y. H. Su, J. Shieh, M. H. Hon, J. Am. Ceram. Soc. 90 (2007) 4073. (c) E. Ozkan, S. H. Lee, P. Liu, C. E. Tracy, F. Z. Tepehan, J.R. Pitts, S.K. Deb, Solid State Ionics 149 (2002) 139. (d) S. Sallard, T. Brezesinski, B. M. Smarsly, J. Phys. Chem. C 111 (2007) 7200. (e) T. Brezesinski, D. F. Rohlfing, S. Sallard, M. Antonietti, Bernd M. Smarsly, Small 2 (2006) 1203.

[17] (a) K. A. Gesheva, T. Ivanova, F. Hamelmann, Solar Energy Mater. \& Solar Cells 90 (2006) 2532. (b) J. Livage, G. Guzman, Solid State tonics 84 (1996) 205. [c] M. Deepa, R. Sharma, A. Basu, S. A. Agnihotry, Electrochimica Acta 50 (2005) 3545.

[18] M. Deepa, A K Srivastava, K N Sood, S. A. Agnihotrym, Nanotechnol. 17 (2006) 2625.

[19] M. Deepa, A.K. Srivastava, S.N. Sharma, Govind, S.M. Shivaprasad, Appl. Surf. Sci. 254 (2008) 2342.

[20] (a) A. Stein, M. Fendorf, T. Jarvie, K. Mueller, A. Benesi, T. Mallouk, Chem. Mater. 7 (1995), 304. (b) G. Janauer, A. Dobley, J. Guo, P. Zavalij, M. Whittingham, Chem. Mater. 8 (1996) 2096.

[21] Z. M. Qi, H. S. Zhou, T. Watanabe, I. Honma, J. Mater. Chem. 14 (2004) 3540.

[22] B. Tian, X. Y. Liu, Z. D. Zhang, B. Tu, D. Y. Zhao, J. Solid State Chem. 167 (2002) 324.

[23] (a) S. Kim, T. R. Pauly, T. J. Pinnavaia, Chem. Commun. 2000, 935. (b) J. Lei · D. Liu · L. Guo · X. Yan $\cdot$ H. Tong, J. Sol-Gel Sci Techn 39 (2006) 169.

[24] J. G. Yuan, Y. Z. Zhang, J. Le, L. X. Song, X. F. Hu, Mater. Lett. 61 (2007) 1114.

[25] R. Solarska, B. D. Alexander, J. Augustynski, J Solid State Electrochem. 8 (2004) 748.

[26] M. Deepa, T. K. Saxena, D.P. Singh, K.N. Sood, S. A. Agnihotry, Electrochimica Acta 51 (2006) 1974. 